\title{
A proteomics approach to identify the differential protein level in cardiac muscle of diabetic rat
}

\author{
Dhanaraj Karthik ${ }^{1}$, Ravichandran Vijayakumar ${ }^{2}$, Kalailingam Pazhanichamy ${ }^{3}$ and Sivanesan \\ Ravikumar ${ }^{\bowtie}$
}

1Department of Biotechnology, PRIST University, Vallam, Thanjavur, Tamilnadu, India; ${ }^{2}$ Aquatic Animal Health and Environment Division, Central Institute of Brackishwater Aquaculture-CIBA (ICAR), Chennai, Tamilnadu, India; ${ }^{3}$ Department of Biotechnology, Periyar Maniammai University, Vallam, Thanjavur, Tamilnadu, India

Background: Cardiovascular proteomics investigation reveals the characterization and elucidation of the novel therapeutic targets and strategies to prevent the development of heart failure associated diabetic complication by using 2DE and MS. Methods: The experimental animals were made diabetic with a single intraperitoneal injection of alloxan (150 $\mathrm{mg} / \mathrm{kg}$ of bw). Albino rats were randomly divided into four individual groups: Group-I control $(n=6)$, group-II alloxan-induced diabetic rats, untreated $(n=6)$, group-III $(n=6)$ and group-IV $(n=6)$ alloxaninduced diabetic rats were treated with aqueous and ethanolic extracts of Cynodon dactylon for 15 days, respectively. Animals were euthanized to collect the heart tissues and blood samples. 2DE sample preparation, gel running and staining ( $n=6$ : each groups) were performed at the same time to avoid variation. The result of six gel images from each group were analyzed and evaluated as one match set with 2D software $(P<0.05)$. Results: The above experiment revealed two up-regulated proteins in group-II i.e. NTF4 and ETFB. Conclusions: NTF4 is a neuro-protective agent for neuro-degenerative diseases. It will prevent diabetic secondary complications, such as diabetic polyneuropathy and cardiomyopathy. ETFB is active in the mitochondria, the energy-producing centres in cells. It is clear from the experiment that because of up-regulation of ETFB more energy is availabile and the electron transfer for heart during diabetes is possible, what leads to reduce the oxidative stress and free-radical formation. The up-regulated proteins reduced CVD that occurred just before overt hyperglycaemia due to administration of $C$. dactylon. This approach established the preliminary reference map for decoding cellular mechanisms linked between pathogenesis CVD and diabetes.

Key words: diabetes mellitus, cardiac muscle proteome, 2D electrophoresis, MALDI-TOF-MS, phylogenetic analysis

Received: 15 October, 2013; revised: 28 March, 2014; accepted: 17 April, 2014; available on-line: 11 June, 2014

\section{INTRODUCTION}

Diabetes is a chronic disorder caused by impaired insulin secretion from the pancreatic beta cells. In India, there were about 32 million diabetic patients in 2000 and by 2030 this number is going to increase to 80 million. The characteristic primary symptom for diabetes is hyperglycaemia, and secondary symptoms are retinopathy, nephropathy, cardiomyopathy, coronary heart disease
(CHD) and stroke (Garber \& Neely, 1983). There are many types of oral hypoglycaemic agents (sulfonylureas and thiazolidinediones) along with insulin for the treatment of diabetes, but they are linked to their own side effects (Langtry et al., 1998). The Diabetes Control and Complications Trial (DCCT) research group stated that the control of blood glucose is an effective strategy in clinical complications of diabetes mellitus, but even an optimal control of blood glucose cannot prevent complications in diabetes, which suggests that an alternative therapeutic approach is needed. In recent years, the use of natural medicine has increased worldwide and it may be used (Prince et al., 1998) as an alternative treatment against different diseases. However, in most of the cases the efficacy of this traditional medicine treatment is yet to be proved. Thus, the study of herbal medicine against diabetes is of great importance in the management of diabetes mellitus without any side effect. There are many plants that have anti-diabetogenic effects, such as Opuntia streptacantha Lem, Trigonella foenum graecum L., Momordica charantia L., Ficus bengalensis L., Polygala senega L., Gymnema sylvestre R., Allium sativum, Citrullus colocynthis, etc. Cynodon dactylon is one among them (Santosh et al., 2008). C. dactylon L. (Pers.) (Family: Poaceae) is an herbal plant commonly known as 'Arugampul' (Tamil name: அருகம்புல்) in Tamilnadu, India. C. dactylon is found in almost all warmer parts of the world. It is a short C4 grass, which is rhizomatous, stoloniferous and water-stress tolerant (Bethel et al., 2006). The various extracts of this plant have been reported to have anti-microbial (Ahmed et al., 1994), anti-inflammatory, anti-cystitis (Uncini \& Tomei, 1999), anti-diuretic (Atmani et al., 2009), anti-hypertensive, anti-viral, anti-hysteria, anti-psychotic and anti-gonorrhoeal (Auddy et al., 2003) activities. C. dactylon is used by traditional healers for purifying blood, anuria, and in conjuctivitis, diarrhoea, gonorrhoea, itches and stomach ache (Muthu et al., 2006). Its root and rhizomes are used as a treatment for depression, vomiting, cough, epilepsy and haemorrhage (Miraldi et al., 2001). Recently, it has been reported that the plant possesses a protective effect against stroptozotocin-induced hepatic injury in rats (Singh et al., 2008). It was ascertained recently, that C. dactylon ihas anti-diabetic, hypolipidaemic and anti-oxidant properties, and contains seven major compounds in aqueous extract and 6 major compounds in ethanolic

e-mail: drravinikesh@yahoo.co.in (S. Ravikumar), kar07bio@gmail. com (D. Karthik)

Abbreviations: CHD, coronary heart disease; DCCT, Diabetes Control and Complications Trial; DC, Diabetic cardiomyopathy; C. dactylon, Cynodon dactylon 
extract. Anti-diabetic activity of $C$. dactylon is related to the presence of 2-propenoic acid and tetra-methyl-2-hexadecen-1-ol (Karthik \& Ravikumar, 2011a, b).

Diabetes is associated with profound changes in cardiac metabolism characterized by modulation of glucose transport, glycolysis, glycogen synthesis, lipid metabolism, protein synthesis, growth, contractility and apoptosis in cardiomyocytes by insulin (Abel, 2005). The impairment of shared insulin signalling pathways in metabolic and cardiovascular tissues contributes to reciprocal relationships between insulin resistance and endothelial dysfunction (Kim et al., 2006). Diabetic cardiomyopathy (DC) is an underlying aetiology of heart failure $(\sim 30 \%$ of all type 1 diabetic patients). The pathological mechanisms associated with DC are still not understood (Lam et al., 2006). The ultimate goal of the study is to identify and define possible causative agents involved in the disease outcome. According to the World Health Organization (WHO), cardiovascular disease resulting in cardiac dysfunction and heart failure is among the leading causes of morbidity and mortality in developed countries (Schott et al., 2010). Although the science of genomics has formed the basis of our understanding of the cellular and molecular mechanisms underlying cardiovascular disease, many downstream processes remain still largely unknown. Further development in proteomic technologies will not only allow the monitoring of changes in protein expression, but also together with genomic data, promise to be valuable in broadening our knowledge of the pathogenic pathways that lead to heart failure (Lien et al., 2006). Proteome analyses related to ischaemic/reperfused and mitochondrial signalling in the myocardium have been used to identify alterations in mitochondrial signalling mechanisms and changes associated with stress response, as well as energy metabolism in mitochondria (White et al., 2005; Yan et al., 2004). Hamblin et al. (2007) characterized cardiac proteome changes as an indicative of DC, and this study may be useful to assess diagnostically the efficacy of anti-oxidant therapies as treatments against diabetes mellitus complications involving the heart problems. Proteomic approaches have been documented in many studies related to clinically useful biomarkers of disease and treatment response (Anderson, 2005; Cruz-Topete et al., 2011).

Proteomic studies can be applied to a range of biological systems including animal models and/or cell culture systems to answer the desired research question. In this study, we review the current status of proteomic technologies and describe how it is applied to unmask the pathophysiological mechanisms associated with diabetesrelated cardiomyopathy.

\section{MATERIALS AND METHODS}

Chemicals. Alloxan was purchased from Sigma chemicals (St Louis, Mo, USA). Ampholyte was purchased from Fluka (St Louis). Protein marker was obtained from Fermentas (St Leon-Rot, Germany). $\alpha$-cyano-4hydroxycinnamic acid was obtained from Bruker Daltonik (Bremen, Germany). Unless otherwise stated, all other chemicals used were from Sigma-Aldrich (St Louis).

Plant collection and extract preparation. Fresh plants of $C$. dactylon were collected in October from the herbal garden of PRIST University, and were identified and authenticated by botanist Rev Dr S John Britto SJ, Director, The Rapinat Herbarium and Centre for Molecular Systematics, St Joseph's College (Autonomous), Tiruchirappalli, Tamil Nadu, India. The voucher specimen of herbarium has been deposited at the Rapinat Herbarium and its number is RHCD02. Leaves of C. dactylon were shade dried at room temperature. Dried plant materials were subjected to size reduction to a coarse powder by using dry grinder. A total of $450 \mathrm{~g}$ of powder was packed into reflection unit apparatus and boiled for $10 \mathrm{~h}$ and $450 \mathrm{~g}$ of powdered plant material was subjected $70 \%$ ethanol in distilled water $(\mathrm{v} / \mathrm{v})$. The two different resulted extracts were filtered and concentrated by rotary evaporator under reduced pressure and a low temperature.

Experimental procedure. Healthy male adult Wister rats (Rat: Rattus norvegicus) weighing 130-150 g were selected for the study. The study was carried in accordance with the rules and regulations laid by the Institutional Animal Ethics Committee (IAEC no.: 743/03/ abc/CPCSEA dt 3-3-2003-approval no.: PhD2/2009-2010). The animals were housed with free access to food and water. Group I, controls $(n=6)$ were fed with normal diet. Albino rats were made diabetic by a single intraperitoneal (i.p.) injection of alloxan dissolved in normal saline at a dose of $150 \mathrm{mg} / \mathrm{kg}$ body weight $(n=30)$. The animals were considered diabetic if their blood glucose values were $>200 \mathrm{mg} / \mathrm{dl}$ on the third day after being injected with alloxan (i.e. after 72 h). After the induction of diabetes, they were randomly divided into individual groups: Group II, alloxan-induced diabetic rats, untreated $(n=6)$; Group III, alloxan-induced diabetic rats, treated with aqueous $C$. dactylon leaves extract at a dosage of $450 \mathrm{mg} / \mathrm{kg} \mathrm{b.w.} \mathrm{daily/orally} \mathrm{for} 15$ days $(n=6)$; and Group IV $(n=6)$ alloxan-induced diabetic rats, treated with ethanolic extract of $C$. dactylon leaves at a dosage of $450 \mathrm{mg} / \mathrm{kg} \mathrm{b.w}$. daily/orally for 15 days. After 15 days of treatment, the animals were euthanized to collect whole heart tissues and blood samples with heparin $(10 \mathrm{IU})$. The blood samples were centrifuged at 6000 $\mathrm{rpm} ; 4^{\circ} \mathrm{C}$ for $10 \mathrm{~min}$ and plasma were collected and then rapidly stored at $-80^{\circ} \mathrm{C}$. Plasma insulin was measured by enzyme-linked immunosorbent assay (ELISA; Mercodia) before and after the induction of diabetes (alloxan) and after the $C$. dactylon treatment.

Sample preparation. Myocardial tissue of control and diabetic rats and both treated groups were immediately frozen in liquid nitrogen and stored at $-80^{\circ} \mathrm{C}$ until use. Each set of animal heart samples (six samples from each groups) were processed in parallel through protein extraction (TCA/acetone method), 2D electrophoresis (2DE) and staining to avoid differences from sample handling. Frozen myocardial tissues taken from control $(n=6)$, and diabetic rats $(n=6)$, and diabetic rats treated with aqueous $C$. dactylon leaves $(n=6)$, and diabetic rats treated with ethanolic extract of $C$. dactylon leaves $(n=6)$ were homogenized in $1 \mathrm{X}$ PBS with protease inhibitor. The homogenate was centrifuged at $10000 \mathrm{rpm}$ for $10 \mathrm{~min} \mathrm{~h}$ at $4^{\circ} \mathrm{C}$. The pellet was discarded, and the protein concentration of the supernatant was determined by using Bradford method (Bradford, 1976). Two milligram of protein sample was mixed with 1:1 ratio volume of $10 \%$ TCA/acetone solution and kept for overnight at $20^{\circ} \mathrm{C}$. Then, centrifuged at $10000 \mathrm{rpm}$ for $15 \mathrm{~min}$ at $4^{\circ} \mathrm{C}$ in a micro-centrifuge and washed with $1 \mathrm{ml}$ icecold acetone four times after discarding the supernatant. The pellet was re-suspended with $200 \mu$ l of lysis buffer (85 mM Tris $\mathrm{pH} 6.8,0.2 \% \mathrm{SDS}$ ).

2DE/imaging/protein identification. Isoelectric focusing (IEF) (O'Farrell, 1975) was carried out with $18 \mathrm{~cm}$ rod gel in $\mathrm{pH} \mathrm{3-10}$ and gel contains $3 \mathrm{~g}$ urea, $7.125 \mathrm{ml}$ distilled water, $2.44 \mathrm{ml}$ acrylamide $(28.38 \%$ acrylamide, $1.62 \%$ bis-acrylamide), $0.750 \mathrm{ml}$ carrier am- 
pholytes 3/10, $0.375 \mathrm{ml} \mathrm{NP}-40,34.625 \mu \mathrm{l}$ ammonium persulphate $(10 \%)$ and $12.5 \mu \mathrm{l}$ TEMED. At the cathode side, $350 \mu \mathrm{g}$ of the samples were loaded and electrophoretic conditions of the rod gels during the IEF were $200 \mathrm{~V}$ for $15 \mathrm{~min}, 300 \mathrm{~V}$ for $30 \mathrm{~min}$ and $400 \mathrm{~V}$ for $16 \mathrm{~h}$. After focusing red gels were equilibrated in $6 \mathrm{M}$ urea, $75 \mathrm{mM}$ Tris/ $\mathrm{HCl} \mathrm{pH} 8.8,29.3 \%$ glycerol, 2\% SDS, $0.002 \%$ bromophenol blue for $30 \mathrm{~min}$ in buffer containing $8 \mathrm{mg} / \mathrm{ml}$ D'T followed by incubation for $30 \mathrm{~min}$ in buffer containing $20 \mathrm{mg} / \mathrm{ml}$ iodacetamide. The 2DE was performed with $12 \%$ polyacrylamide gels in 250 $\mathrm{V}$ for about $4 \mathrm{~h}$. The analytical gels were stained with Coomassie blue. The protein $\mathrm{Mr}$ and $\mathrm{pI}$ were estimated by using SDS/PAGE protein standard with a molecular mass range from 10 to $170 \mathrm{kDa}$ and a $\mathrm{pH}$ range from 3 to 10 . The gel image were captured by gel doc image system and analysed by Melanie Viewer $72 \mathrm{D}$ software. The altered proteins were excised, and the identification by mass spectrometry (MALDI-TOF-MS) is described below.

MS analysis (MALDI-TOF-MS). Proteins of interest were excised, de-stained with $10 \mathrm{mM}$ ammonium bicarbonate solution containing $50 \%(\mathrm{v} / \mathrm{v})$ acetonitrile and dried in a Speed Vac centrifuge. The polypeptides were reduced $(10 \mathrm{~mm}$ DTT, $100 \mathrm{~mm}$ ammonium bicarbonate for $30 \mathrm{~min}$ at $\left.56^{\circ} \mathrm{C}\right)$, alkylated $(50 \mathrm{~mm}$ iodoacetamide, $100 \mathrm{~mm}$ ammonium bicarbonate for or $30 \mathrm{~min}$ in dark room temperature) and digested with sequencing grademodified trypsin $(10 \mathrm{ng} / \mu \mathrm{l}$ in $5 \mathrm{mM}$ ammonium bicarbonate). After incubation for $5 \mathrm{~h}$ at $37^{\circ} \mathrm{C}$, the reaction was stopped by adding $1 \mu \mathrm{l}$ of $1 \%$ TFA. The digested peptides were directly mixed with $1: 1$ ratio of MALDI matrix, i.e. $10 \mathrm{mg} / \mathrm{ml} \mathrm{CHCA} \mathrm{in} \mathrm{50 \%} \mathrm{acetonitrile} \mathrm{and}$ $0.1 \%(\mathrm{v} / \mathrm{v})$ trifluoroacetic acid and allowed to dry in open air. Tryptic peptides were analysed with a MALDI-TOF mass spectrometer (Bruker-Daltonics, Germany) in positive mode. The samples were analysed in a MALDI-TOF mass spectrometer equipped with linear positive mode $25 \mathrm{KvA}$, laser shots $150[337 \mathrm{~nm}, 50 \mathrm{~Hz}$, N2 laser (Bruker-Daltonics, Germany)] and mass spectra were acquired using the flexanalysis software. Spectra were analysed using the $\mathrm{m} / \mathrm{z}$ program and contaminant peaks (keratin and trypsin) were removed manually. The remaining peaks were then matched with the theoretical peptide masses using MASCOT (Matrix Science, http:// www.matrixscience.com/). The search was performed against Rattus database with considered 0.1Da peptide tolerance, one missed cleavage allowed, carbamidomethyl (C) of cysteine (fixed modifications) and oxidation of methionine (variable modifications). Molecular Weight Search (MOWSE) scores from database interrogation above $30 \quad(P<0.05)$, number of matched ions, number of matching ions with independent MS/MS matches, percent protein sequence coverage, and correlation of gel region with predicted MW and pI were collectively considered for each protein identification (Perkins et al., 1999).

Alignment and phylogenetic analyses of identified proteins. Multiple sequence alignments were performed with clustalX (2.0.10) and the output of the alignments was formatted by clustalX. The phylogenetic tree was calculated using Neighbor-Joining method (NJ method) integrated in clustalX, then visualized with Treeview 32 with 1000 bootstrap replicates (Kumar et al., 2004).

Statistical analysis. Data were expressed as the mean \pm S.E.M. and were statistically evaluated using analysis of variance (ANOVA). The value $P \leq 0.05$ was considered statistically significant.

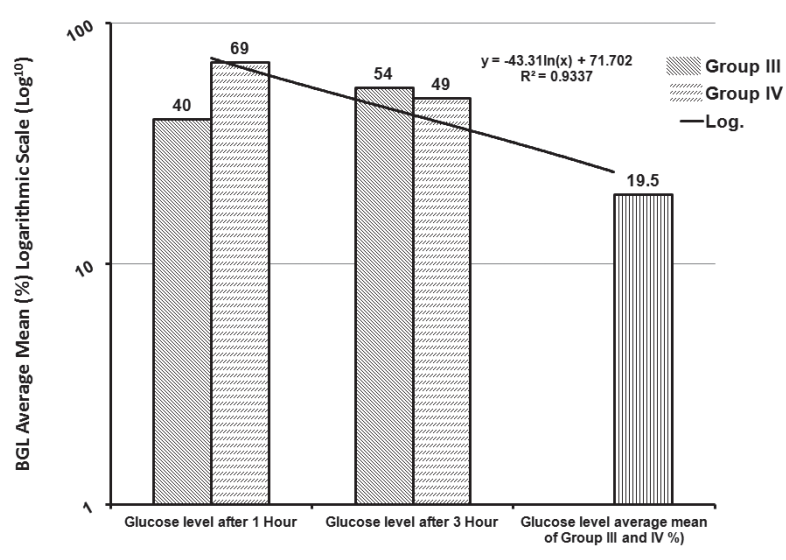

Figure 1a. Effect of aqueous and ethanolic extract of $C$. dactylon leaves on plasma glucose levels in alloxan-induced diabetic rat after feeding glucose $(10 \mathrm{~g} / \mathrm{kg})$.

Values are expressed mean \pm S.E.M. of six animals. $P<0.05$ as compared with diabetic induced group.

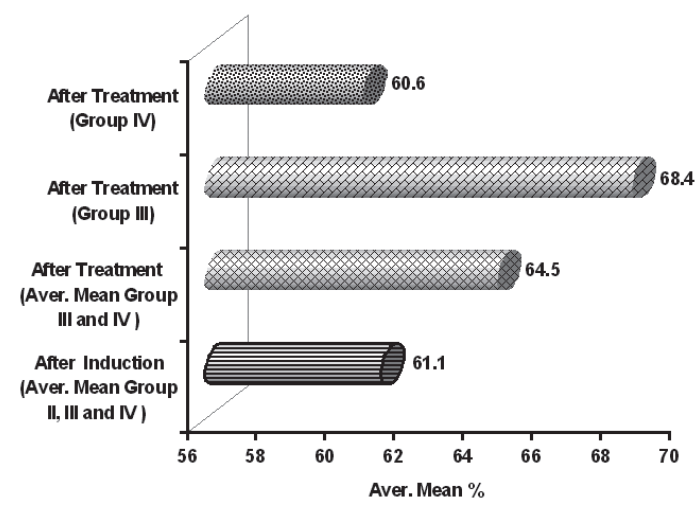

Figure 1b. Effect of aqueous and ethanolic extract of C. dactylon leaves on plasma insulin levels in alloxan induced diabetic rat. Values are expressed mean \pm S.E.M. of six animals. $P<0.05$ as compared with diabetic induced group.

\section{RESULTS}

\section{Plasma glucose and insulin level}

The significant difference between the mean values of insulin and glucose levels between the control and diabetic rats are shown in Figs. $1 \mathrm{a}$ and $1 \mathrm{~b}$. There was a significant decrease in the levels of plasma insulin and significant increase in the levels of plasma glucose in diabetic rats as compared with control $(P<0.05)$. In this experiment, the plasma insulin levels before the induction of diabetes were same in all groups, whereas plasma insulin levels after induction of diabetes were significantly decreased as compared with control $(P<0.05)$. This indicates that alloxan efficiently destroyed the $\beta$ cells of pancreas, which in turn decreased plasma insulin (average mean 61.1\%), and increased glucose levels, and caused diabetes. The administration of $C$. dactylon leaf extract to diabetic rats resulted in a significant increase in plasma insulin (Group III: 68.4\%; Group IV: 60.6\%; average mean $64.5 \%$ ) and significant decrease glucose levels $(P<0.05)$. Treatment with the aqueous extract of C. dactylon leaves to diabetic rats resulted in a significant decrease of $7.8 \%$ more than ethanolic extract. Based on the validation procedure, we concluded that the plasma insulin and glucose values obtained in this experimental research would be useful for further studies. 


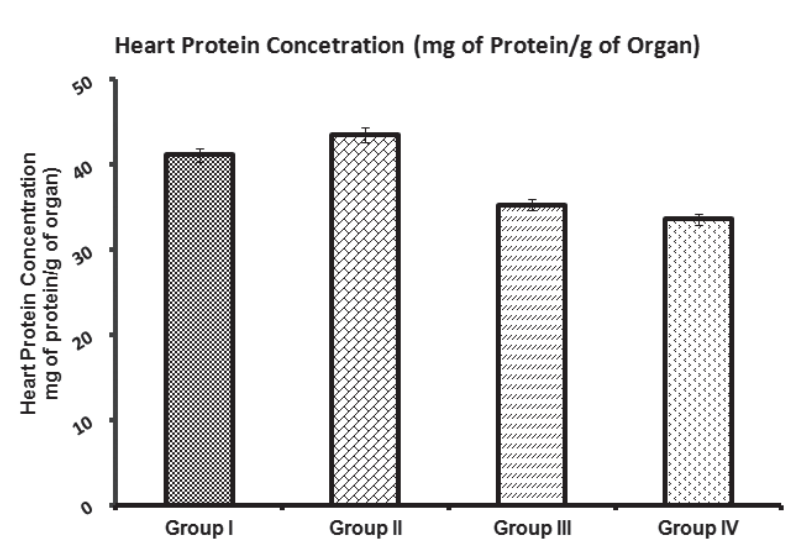

Figure 2. Effect of aqueous and ethanolic extract of $C$. dactylon leaves on total proteins in alloxan-induced diabetic rat heart. Values are expressed mean \pm S.E.M. of six animals. $P<0.05$ as compared with diabetic induced group.

\section{Differentially expressed proteins analyses by 2DE}

In an effort to gain an insight into the molecular mechanisms underlying the pathogenesis of DC, we performed a comparative analysis of the cardiac protein expression profiles of control and diabetic rats following alloxan-induced diabetes using $2 \mathrm{DE}$ and mass spectrometry (2-DE/MS). Each set of animal heart samples (six samples from each groups) were processed through protein extraction (TCA/acetone method), 2DE and staining simultaneously to avoid differences from sample handling. The resulting six gel images (for each group) were analysed and evaluated as one match set with the 2D software, i.e. Melanie Viewer $7(P<0.05)$. The total protein content of rat heart is indicated in Fig. 2. Average amounts of $350 \mu \mathrm{g}$ of total proteins from each sample were loaded for 2-DE investigations. On the average, 725 matched spots were detected on each gel and two proteins were differently expressed in alloxan-
Table 1. For group with six samples of replicate, gels were chosen to create merged images and the resulting mean spot volumes were plotted against each other.

As expected average correlation coefficient, this gave a straight line $\left(R^{2}\right.$ 0.8). Values are expressed as mean \pm S.E.M. of six animals. The value $P<0.05$ is statistically significance.

\begin{tabular}{lllll}
\hline \multicolumn{4}{l}{ Spot intensity variability in six set of gels } \\
\hline Groups & $\begin{array}{l}\text { Total } \\
\text { spots }\end{array}$ & $\begin{array}{l}\text { Average } \\
\text { cor. coef. }\end{array}$ & Mean S.D. & $\begin{array}{l}P \text { value } \\
(P<0.05)\end{array}$ \\
\hline Group I $(n=6)$ & 725 & 0.81 & \pm 12.00 & 0.034 \\
\hline Group II $(n=6)$ & 723 & 0.86 & \pm 15.00 & 0.029 \\
\hline Group III $(n=6)$ & 727 & 0.89 & \pm 14.00 & 0.041 \\
\hline Group IV $(n=6)$ & 724 & 0.83 & \pm 10.00 & 0.025 \\
\hline
\end{tabular}

induced diabetic rats (group II) as compared to control and diabetic treated groups using Melanie Viewer 7 $2 \mathrm{D}$ software. Figure 3 shows one set of $2 \mathrm{DE}$ gels (six samples for each groups), where differentially expressed proteins are marked with arrow and close-up 3D view of differentially expressed proteins. Numbers of spots, average correlation coefficient and mean S.D. for spot intensities from each set of gels are shown in Table 1 $(P<0.05)$. Figure 3 gives a SDS/PAGE detailed overview of proteins with respect to molecular weight, but could not find any differentially expressed proteins between the groups. The heart protein patterns observed for each sample were similar and reproducible from animal to animal and gel to gel.

\section{Differentially expressed proteins identification by MALDI-TOF-MS}

In order to identify the altered proteins, the protein spots were excised from the $2 \mathrm{DE}$ gels and analysed by MALDI-TOF-MS. By using in-gel digest and MS with consecutive database search, we identified two differentially expressed proteins. Figure $4 \mathrm{a}$ and Fig. $4 \mathrm{~b}$ show an
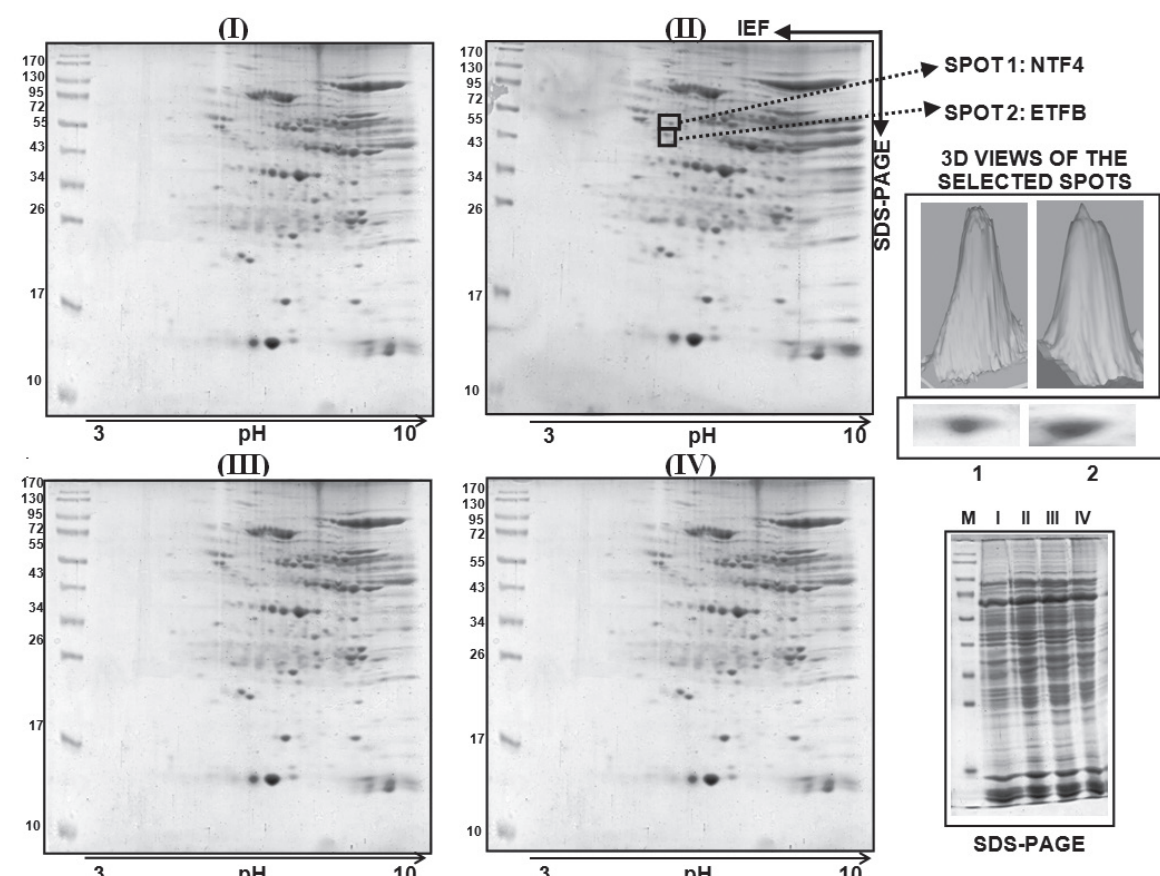

Figure 3. Comparison of 2DE patterns of rat cardiac proteome. Group I (Control); Group II (alloxan diabetic, untreated); Group III (alloxan diabetic rats treated with aqueous extract) and Group IV (alloxan diabetic rats treated with ethanolic extract). 


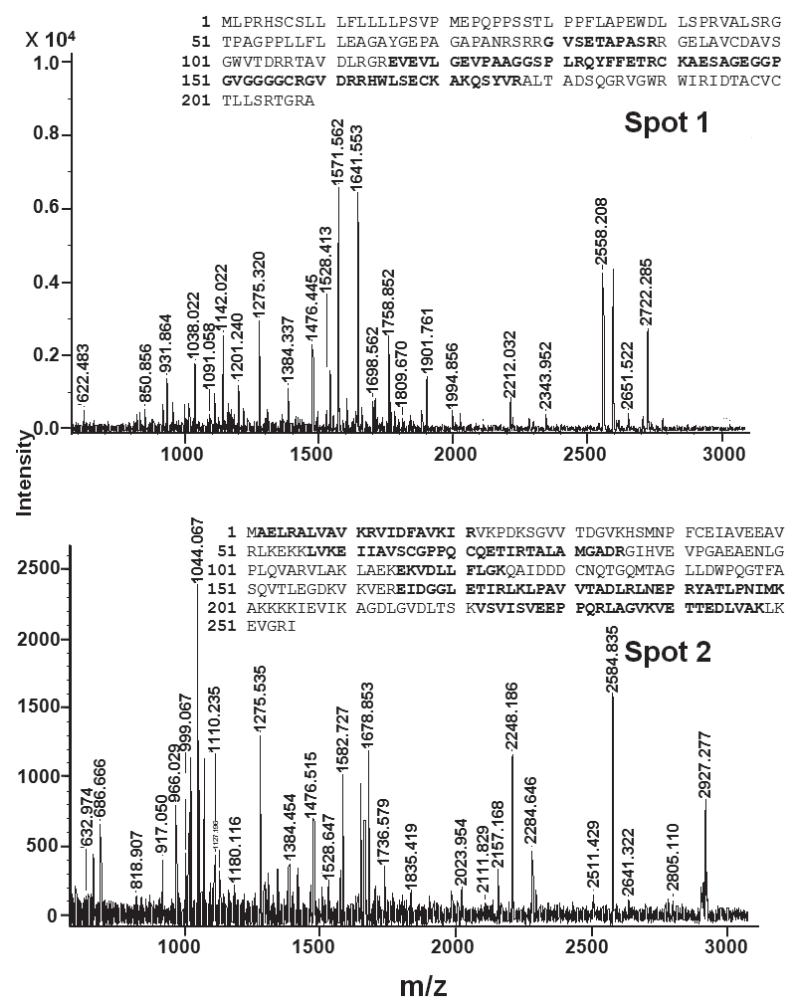

Figure 4a. MALDI-TOF-MS peptide mass fingerprints (reflection mode) of tryptic digest of Neurotrophins (Spot 1) and ETFB (Spot 2).

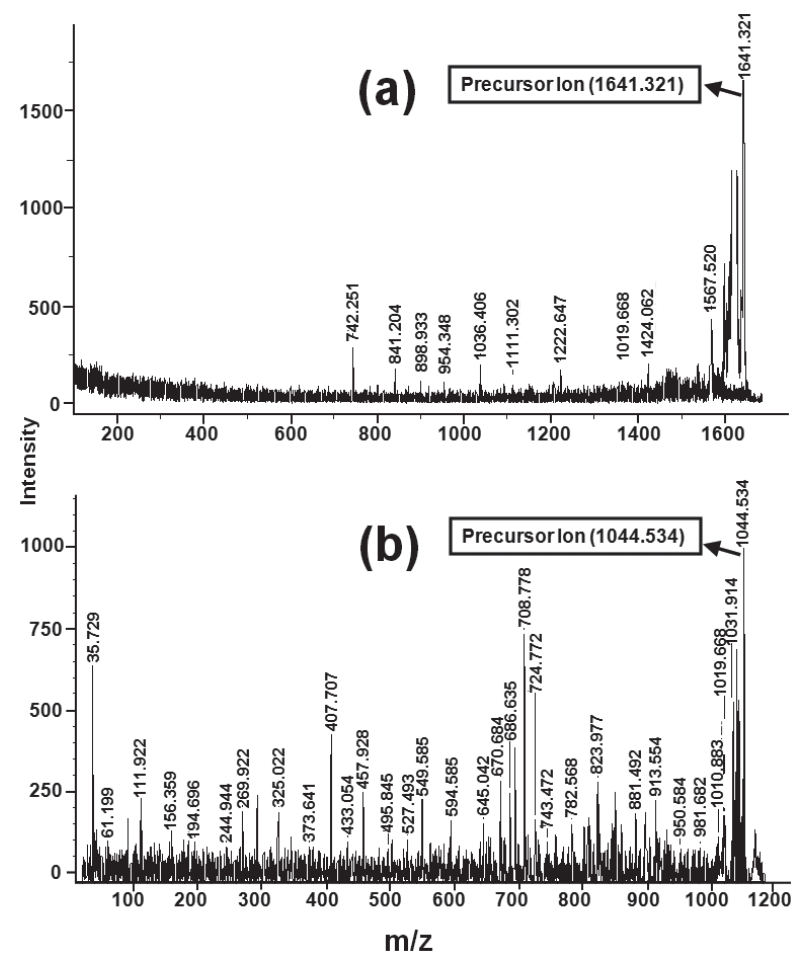

Figure 4b. MALDI-TOF-MS/MS spectrum of a peptide with a mass of 1641.321 Da (Precursor ion) selected from the peptide mixture of Neurotrophins (a) and mass of 1044.534 Da (Precursor ion) selected from the peptide mixture of ETFB (b).

Table 2. Detected peptides by MALDI-TOF-MS analysis from individual separated polypeptides after trypsin digestion.

\begin{tabular}{lllllllll}
\hline A. No. & Protein name & Score & Sequ. cov. (\%) & Esti. MW (Da) & Esti. pl & II & Al & GRAVY \\
\hline P34131 & NTF4 & 35 & 34 & 22718 & 9.17 & 68.94 & 81.72 & -1.173 \\
Q68FU3 & ETFB & 42 & 47 & 27898 & 7.60 & 24.02 & 107.76 & -0.076 \\
\hline
\end{tabular}

example of a MALDI-TOF-MS peptide mass fingerprint of the tryptic digests corresponding to spots 1 and 2 . Table 2 gives a detailed overview of these two proteins with respect to observed and expected molecular weight and $\mathrm{pI}$ value, and the mode of identification with matched peptides. The MS analysis identified two proteins, i.e. spot 1 is neurotrophins (NTF4), having molecular weight $22.7 \mathrm{kDa}$ and iso-electric point 9.1; and spot 2 is electron transfer flavoprotein beta subunit (ETFB), having molecular weight $27.8 \mathrm{kDa}$ and iso-electric point 7.6. A review of the literature shows that most of these proteins are closely related to cardiac metabolism and function. The cellular locations of these proteins were determined using UniProt, and proteins were associated with many subcellular locations with the largest number associated with the cytoplasm and mitochondria in heart. These results indicate that cardiac function may be modified during type I diabetes. The identified proteins were classified into two groups based on their biological function: (i) Neurotrophic cascade protein (NTF4) and (ii) Electron transport chain cascade protein (ETFB).

\section{Phylogenetic analyses of the NTF4 and ETFB}

For phylogenetic analyses, the collected protein sequence of NTF4 and ETFB were aligned with ClustalX software. With the aim to evaluate the results for phylogenetic similarity between rat and other closest species, protein sequences were collected from NCBI protein blast database. The phylogenetic tree was constructed by the NJ method with 1000 bootstrap replicates. The multiple sequence alignments of the NTF4 and ETFB in rat, mouse, human, cattle and house are shown in Fig. 5a. All NTF4 and ETFB protein sequences share a conserved core with $\mathrm{C}$-terminal and core region of each NTF4 and ETFB and varied $\mathrm{N}$-terminal sequences. In this analysis, it is apparent that NTF4 and ETFB protein sequence are conserved with rat and mouse (91.7\% similar and 100\% similar, respectively). The human and cattle were formed in different node with respect to different percentage similarity. In this division, it is apparent that NTF4 and ETFB of different species are most closely related to rat. The phylogenetic analyses of the NTF4 and ETFB are shown in Fig. $5 b$.

\section{DISCUSSION}

The observed significant increase in the level of blood glucose could be related to the destruction of pancreatic beta cells by alloxan. With the supplementation of aqueous and ethanolic $C$. dactylon extracts for 2 weeks, fasting blood glucose level was significantly different with diabetic rats. Thus, the present study provides substantial evidence on the hypoglycaemic action of aqueous and 
CLUSTAL 2.0.10 Multiple sequence Alignment

\begin{tabular}{|c|c|c|c|}
\hline \multicolumn{2}{|r|}{ Neurotrophin } & \multicolumn{2}{|r|}{ Electron Transfer Flavoprotein Subunit Beta } \\
\hline Rattus & & \multirow{5}{*}{\multicolumn{2}{|c|}{ 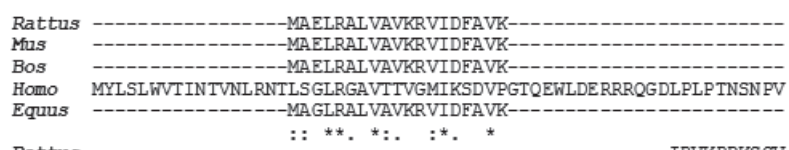 }} \\
\hline Mass & -DVREETTCILQRGPTQPGG PQSQSEEVEVLLLT -G & & \\
\hline Homo & - & & \\
\hline \multirow[t]{3}{*}{ Equus } & $\begin{array}{l}\text { MGDPGLLKCG PSGTRVSRPAPPPPHVRKE GVTCVPSRGP PEPGG PQPRS SEVEEVLTGPV } \\
\end{array}$ & & \\
\hline & & & \\
\hline & --MT PRHSCST-LLFTLLLPSYPMEPOPPSSTL PPFT APFWDI & Rattus & -IRVKPDKSGV \\
\hline $\begin{array}{l}\text { Rattus } \\
\text { Mus }\end{array}$ & $\begin{array}{l}--- \text { ML PRHSCSL-LLFLLLLPSVPMEPQP PSSTL PPFLAPEWDI } \\
\text { VOAML PRHSCSL-LLFLFLLPSVPMEPHP PSSTL PPFLA PEWDI }\end{array}$ & & \\
\hline Homo & $\begin{array}{l}\text { VQAML PRASCSL-LLFLFLLPSVPMEPHP PSSTLPPFLAAPWD } \\
---M L \text { PLPSCSLPI LLLFLLPSVP IESQP PPSTL PPFLA PEWD }\end{array}$ & $\begin{array}{l}\text { Bos } \\
\text { Homo }\end{array}$ & LSLELCDPGQGPAP FQAVVVLIQPGRGLALRPPP SCLFP PDPTPSPPAGQIRVKPDRTGV \\
\hline & LSEML PHPSG SLPI LLLFL LPSVPMEPHP PPSPL PPFPA PEW & Equus & $----T R Q I$ PDRT FV \\
\hline \multirow[t]{2}{*}{ Equus } & LSEMR PHPSCSVPI LLLFLLPSVPMEPHP PPSPL PPFPA PEWDLLSPRVALSRGAPAG PP & & $* * *:: *$ \\
\hline & & & \\
\hline Rattus & LLFLLEAGAYGEPAGAPANRSRRGVSETA PASRRGELAVCDAVSGWVTDRRTAVDLRGRE & & VTDGVKHS-MNPFCEIAVE EAVRL KEKKLVKEII AVSCG PSQCQETIRT ALAMGGADRG IH \\
\hline & LLFLLEAGAYGEPAGAPANRSRRGV: & Bos & VIDGVKHS-MNPFCEIAVE EAVRL KEKKLVVKEI I AVSCG PAQCQETIR \\
\hline Homo & LLFLLEAGAFRESAGAPANRSRRGV & Homo & VTDGVKHS-MNPFCEIAVE EAVRL KEKKLVKEVI AVSCG PAQCQETIRT ALAMGMDRG IH \\
\hline Bos & LLFLLESGAF GEPVGSPANRSRRGVSETA PASRRGELAVCDAVSGWV & Equus & SSRTAXTSPQNPISDSAVE EAIRL KEKNLEKEILAIRSG PLPYLETIRTAL_AMGADRG IH \\
\hline \multirow[t]{2}{*}{ Equus } & 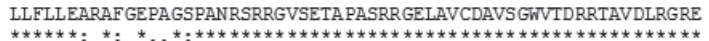 & & : . $\quad * * *: .: * * * * *: * * * * *: * * *:: *$ :.$^{* *} \quad * * * * * * * * * * * * * * * *$ \\
\hline & & & VEVPGAEAENLGPLQVARVLAKL_AEKEKVDLLFLGKQAI DDDCNQTGQMTAGLLDWPQGT \\
\hline Rattus & VEVLGEVPAAGGSPLRQYF FETRCKAESAGEGGPGVGGGGCRGVDRRHWLSECKAKQSYV & & VEIPGAQAESLGPLQVARVLAKLAEKEKVDLLF \\
\hline Mas & VEVLGEVPAAGGSPLRQYF FETRCKR & Bos & VEVPAAEANHLGPLQVARVLAKL_AEKEKVDLVLL GKQAI DDDCNQTGQMTAGFLDWPQGT \\
\hline Homo & VEVLG & Homo & VEVPPAEAERLGPLQVARVLAKLAEKKEKVDLVLI \\
\hline Bos & VEVLGEVPAAGGSPLRQYFFETRCK & Equus & VEVPAAEADRLGPLQVARVLAKI \\
\hline \multirow[t]{2}{*}{ Equus } & VEVLGEVPAAGGSPLRQYF FETRCKADSAGEGGPGGGGGGCRGVDRRHVSECKAKQSYV & & 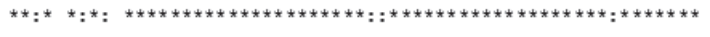 \\
\hline & ( & & \\
\hline Rattus & RVGWRWIRIDTACVCTLLSRTGRA & & FASQVTLEGD KVKVEREID GGLETLRLKL PAVVI ADLRLNEPRY ATLPN IMKAKKKKI EV \\
\hline & RALTA & Bos & FASQVTLEGD KI KVEREID GGLET LRLKL PAVVT ADLRL NEPRY ATL PN IMKAKKKKI EV \\
\hline Homo & RALTA & Homo & FASQVTLEGDKLKVEREIDGGLETLRLKL PAVV \\
\hline & RALTT & Equas & FASQVTLEGDKVKVEREIDGGLE \\
\hline \multirow[t]{7}{*}{ Equus } & $\begin{array}{l}\text { RALTTDAQGRVGWRWIRIDTACVCTLLSRTGRA } \\
* * * * * * * * * * * * * * * * * * * * * * * * * *\end{array}$ & & $* * * * * * * * * * * * * * * * * * * * * *$ \\
\hline & & Rattus & IKAGDLGVDLTSKVSVISVEEPPQRL_AGVKVETTEDLVAKLKEVGRI \\
\hline & & & VKAGDLGVDLTSKVSVISVEEPPQRSAGVKVETTEDLVAKLKEVGRI \\
\hline & & & IKAGDLGVDLTSKL SVISVEDPPQRTAGVKVETTEDLVAKLKEI GRI \\
\hline & & & \\
\hline & & Equas & IKPGDLGVDLTSKL SVVSVEDPPERTAGVKVETTEDLVAKLKEVGRI \\
\hline & & & $* * * * * * * * *$ \\
\hline
\end{tabular}

Figure 5a. Screen display of multiple sequence alignment of different species protein sequence of Neurotrophins and ETFB aligned by NJ method by using ClustalX.

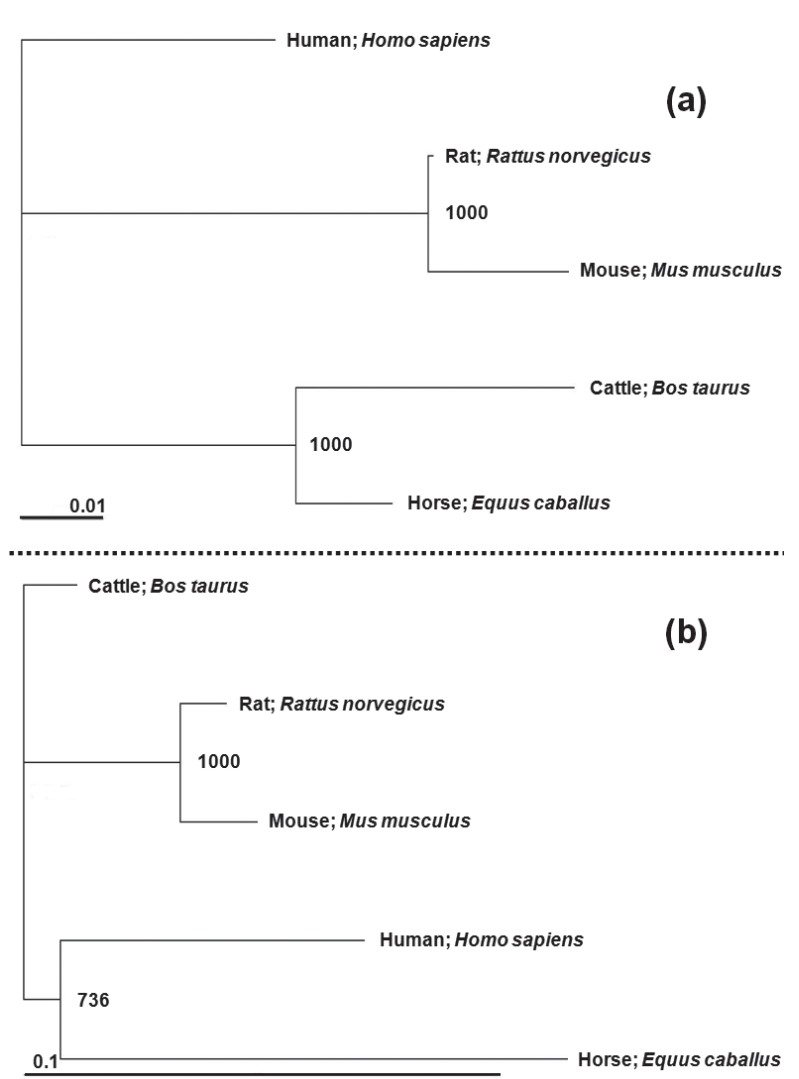

Figure $5 \mathrm{~b}$. The phylogenetic tree based on the $\mathrm{NJ}$ method by using ClustalX and treeview with 1000 bootstrap replicates. Neurotrophins (a) and ETFB (b). ethanolic extract of $C$. dactylon in alloxan-induced diabetic rats (Karthik \& Ravikumar, 2011a, b).

Cardiac disease is the leading cause of mortality associated with diabetes mellitus. The causes of heart diseases associated with diabetes are not yet understood and/or mechanisms are still unknown, but the profound reason could be the variation of gene and protein expression (Noble, 2002). Proteomics is a powerful technique that provides a record of intact proteins and can reveal changes in the levels of protein between samples. Therefore, it is likely to provide new insights into cellular mechanisms involved in cardiac dysfunction and new diagnostic and therapeutic markers ('Tuñón et al., 2010; Ares-Carrasco et al., 2012). Our results also support the above statement and indicate that cardiac function may be modified during diabetes. The identified proteins were classified into two groups based on their biological function; (i) Neurotrophic cascade protein (NTF4) and (ii) Electron transport chain cascade protein (ETFB). The schematic representation of functional pathways of NTF4 is shown in Fig. 6.

\section{Neurotrophic cascade protein (NTF4)}

Neurotrophins (NTF4) are a family [brain-derived neurotrophic factor (BDNF); neurotrophin-4/5 (NT-4/5), neurotrophin-3 (NT-3) and nerve growth factor (NGF)] of soluble polypeptides, implicated in several functions of the nervous system, including axonal growth, synaptic plasticity, survival, differentiation and myelination. Although originally discovered in the nervous system, many members of the neurotrophin family are expressed in a variety of non-neuronal systems including the cardiovascular, immune, endocrine and reproductive systems (Tessarollo, 1998). NTF4 gene is located on the long (q) 


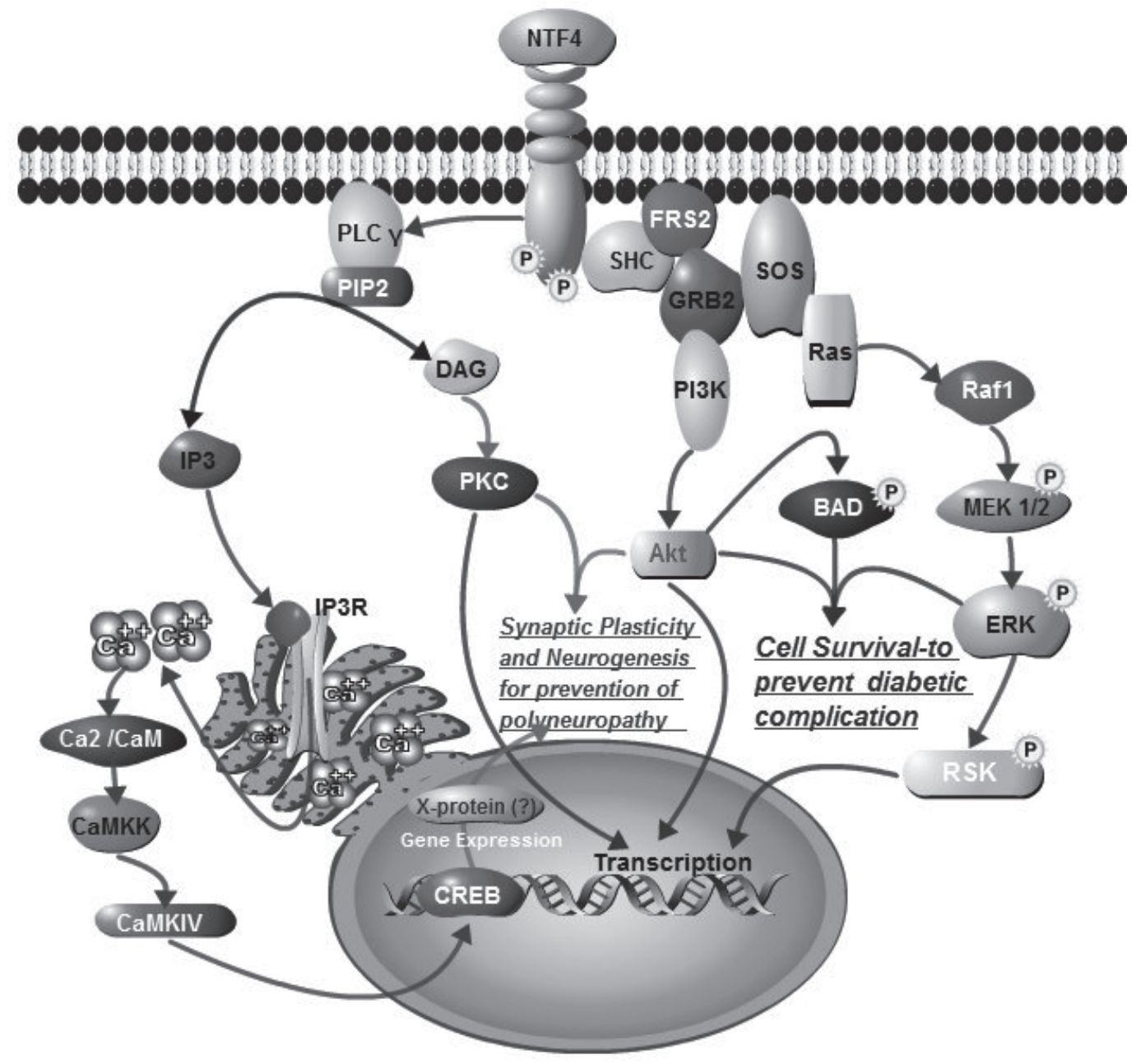

Figure 6. The schematic representation of functional pathways of Neurotrophin 4 (NTF4). Abbreviation: PI 3-K, Phosphatidylinositol 3-Kinase; PIP-2, Phosphatidylinositol 4,5- Bisphosphate; PIP-3, Phosphatidylinositol (3,4,5)-trisphosphate; DAG, Diacylglycerol; PKC, Protein Kinase C; IP3, Inositol $(1,4,5)$-trisphosphate; IP3P, Inositol $(1,4,5)$-trisphosphate Receptor; PI3K, Phosphoinositide-3-Kinase; $\mathrm{CaM}$, Calmodulin; CaMKK, Calmodulin-Dependent Protein Kinase Kinase; CaMKIV, Calcium/Calmodulin-Dependent Protein Kinase Type IV; CREB, CAMP Response Element Binding Protein; FRS2, Fibroblast Growth Factor Receptor Substrate 2; GRB2, Growth Factor Receptor-Bound Protein 2; ERK: Extracellular Signal-Regulated Kinase; MAPK: Mitogen Activated Protein Kinase.

arm of chromosome 19 at position 13.3. More precisely, NTF4 gene is located from base pair 49,564,396 to base pair 49,568,234 on chromosome 19. These neurotrophins are initially synthesized as larger precursors that are proteolytically cleaved to release the mature neurotrophins. The neurotrophins can be distinguished based on their distinct patterns of spatial and temporal expression as well as their differing effects on neuronal targets (Kaisho et al., 1990). NTF4 binds to specific high affinity receptors of the Trk family proteins (TrkB). Besides the presence of the $\mathrm{p} 75$, which binds all neurotrophins with similar affinity (Barbacid, 1993), a receptor tyrosine kinase, that is triggered by its ligand, the BDNF, regulates neuronal cell survival, neurite outgrowth, synaptogenesis and synaptic activity. The up- and down-regulation of NTF4 in diabetic patients cause diabetic poly-neuropathy that can lead to atrophy and weakness of distally located striated muscles due to denervation (Andreassen et al., 2009). Defects in NTF4 may be associated with susceptibility to primary open angle glaucoma (POAG) type 10 (GLC1O). POAG is characterized by a specific pattern of the optic nerve and the visual field defects (Liu et al., 2010). NTF4 has been tested as neuroprotective agent for neurodegenerative diseases like cerebral ischaemia (Lindvall et al., 1994). NTF4 is acting as a survival and activation factors for eosinophils in patients with allergic bronchial asthma (Nassenstein et al., 2003). NTF and their receptors are expressed by the developing heart and vessels. In particular, BDNF deficiency reduces endothelial cell-cell contact in the mouse embryonic heart, thus leading to intra-ventricular wall haemorrhage and depressed cardiac contractility (Donovan et al., 2000). Our results also support the above statement based on the up-regulation of NTF4 in diabetic group which leads to reduce the diabetes complications associated with cardiovascular tissues and down-regulation of NTF4 in diabetic-treated groups with $C$. dactylon which leads to normal cardiac metabolism and function. NTF4 has been acting as neuroprotective agent for neurodegenerative diseases with respect to diabetes and its secondary complications associated with cardiovascular system such as diabetic polyneuropathy and DC. The possible mechanism related to NTF4 action and prevention of the heart from diabetic complication could be the activation of transcription process in nucleus through NTF4 and MAK pathway; NTF4 and AKT pathway; and NTF4 and PKC 
pathway and regulate survival of neuronal cells as well as cardiac cells.

\section{Electron transport chain cascade protein (ETFB)}

ETFB part of an enzyme called electron transfer flavoprotein (ETF) is active in mitochondria, the energy producing centres in cells. ETF is involved in the process by which fats and proteins are broken down to produce energy. ETFB gene is located on the long (q) arm of chromosome 19 at position 13.3. More precisely, ETFB gene is located from base pair 51,848,408 to base pair $51,869,671$ on chromosome 19 (White et al., 1996). ETF is a soluble mitochondrial flavoprotein. It is a dimer of non-identical subunits. ETF serves as a specific electron acceptor for several dehydrogenases. ETFs consist of $\alpha \beta$ heterodimers with a single FAD thought to be bound to the $\mathrm{N}$-terminal region of the $\beta$-subunit (Herrick et al., 1994). Both $\alpha$-subunits ( $\alpha$-ETF, 32000 molecular weight) and $\beta$-subunits $(\beta$-ETF, 27000 molecular weight) were nuclear coded and synthesized in the cytosol. $\alpha$-ETF was synthesized as a precursor ( $\mathrm{p} \alpha$-ETF), 30000 molecular weight larger than its mature counterpart and was translocated into the mitochondria and processed to the mature $\alpha$-ETF. The newly synthesized $\beta$-ETF was the same as the mature $\beta$-ETF (Ikeda et al., 1986). ETF is a key enzyme in the mitochondrial fatty acid beta oxidation and amino acid degradation pathways, which transfers electrons from at least 12 dehydrogenases via ETF-QO to the respiratory chain. Hence, ETF and ETF-QO are functionally interdependent and both are required for electron transfer from the flavoprotein dehydrogenases to the main respiratory chain (Henriques et al., 2010). The mutational analysis of ETF genes demonstrated ETFB missense mutation $124 \mathrm{~T}>\mathrm{C}$ in exon 2 leading to replacement of cysteine-42 with arginine (C42R) and a 604_606AAG deletion in exon 6 in ETFB gene resulting in the deletion of lysine-202 (K202del). Multiple acyl-CoA-dehydrogenase deficiency (MADD) or glutaric aciduria type II (GAII) is a group of metabolic disorders due to deficiency of ETF. These metabolic disorders are characterized by severe acidosis, hypoglycaemia and, often, neonatal death (Curcoy et al., 2003). The associated ETF metabolic disorders and/or reduction of multiple mitochondrial inner membrane enzyme leads to cause various secondary diabetic complication, such as insulin resistance and $\beta$-cell dysfunction.Those inner membrane proteins are mainly involved in mitochondrial OxPhos, and include key enzymes in TCA cycle, $\beta$-oxidation, glutamate metabolism and electron transport chain. Mitochondrial dysfunction has been implicated as a key factor in the development of diabetes (Hongfang et al., 2010). In conclusion, based on our analysis of the proteomic in alloxan-induced diabetic rats, we propose the following sequence of events for the reduction of diabetes-associated complication, which is related to cardiovascular diseases (CVD) and coronary heart disease (CHD). In the absence of glucose inside the cell (due to lack of insulin in diabetic condition), the cells had to survive using alternative energy source. Fatty acid and protein are the main resource of energy in the absence of glucose to balance the normal cardiac function. Interestingly, many of the observed up- and down-regulated proteins reduced CVD and CHD that occurred just before overt hyperglycaemia due to administration of $C$. dactylon leaf extract. Therefore, this experimental result suggests that diabetes complication may improve CVDs management.
In conclusion, proteomics has emerged as an essential method for decoding cellular mechanisms and tools to investigate signal transduction, metabolic and cellular mechanism, biomarker development, phenotype analysis and pathogenesis of heart disease connected to diabetes mellitus. As per our current and previous studies, we explore the importance of phytomedicine and proteomics to unmask the hypothesis of protein-drug target for effective treatment of diabetes, and this approach facilitates an understanding of the cell functioning in normal and diseased states. With the increasing incidence of diabetes mellitus worldwide, we have investigated anti-diabetic activity, hypolipidaemic and anti-oxidant activities of $C$. dactylon in alloxan-induced diabetic rats in our previous studies. Based on GC-MS study, seven major phyto-chemical constituents were present in aqueous extract and six major phyto-chemical constituents were present in ethanolic extract. Anti-diabetic activity of $C$. dactylon is exhibited due to the presence of 2 -propenoic acid and tetra-methyl-2-hexadecen-1-ol. This comprehensive anti-diabetic activity analysis has revealed the identification of potential phytotherapy for diabetes and has given the preliminary map of listed phyto-chemical constituent from aqueous and ethanolic extracts of $C$. dactylon. The identification of phyto-chemical constituent of diabetes did not provide the complete set for clinical therapeutics. Hence, it is needed to evaluate the phyto-chemical target, i.e. identification and characterization of target proteins for target drugs. The study of phyto-medicine and proteomics may unmask the hypothesis of protein-drug target for effective treatment of diabetes, and this approach facilitates an understanding of the cell functioning in normal and diseased states. Our current studies focus on the identification of differentially expressed proteins in alloxan-induced diabetic rats with the treatment of $C$. dactylon plant extract. In this current study, analysis of the proteomic in alloxan-induced diabetic rats reveals that the consequence of events for diabetes-associated CVD complication were reduced by the down-regulation of NTF4 with the effect of administration of $C$. dactylon leaf extract . Interestingly, many of the observed up- and down-regulated proteins reduced CVD and CHD occurred just before overt hyperglycaemia due to administration of $C$. dactylon leaf extract, and therefore, suggest that diabetes complication may improve CVD management. The combined phytomedicine and proteomics approach established the preliminary reference map for decoding cellular mechanisms linked pathogenesis of heart disease connected to diabetes mellitus.

\section{STUDY LIMITATIONS}

Coomassie Blue $\mathrm{R}$ and $\mathrm{G}$ have become most reputed dye in protein detection (PAGE) due to low cost, ease of use and compatibility with downstream application such as MALDI. The detection limits for Coomassie Blue are 10-12 ng. Coomassie Blue provides a significance response with amount of protein load over a 5-25 fold range of concentration, i.e. protein concentration verses detection sensitivity (Wayne \& Patton, 2002).

\section{Conflict of interest}

The authors are not having any conflict of interest.

\section{Acknowledgements}

This work was not financially supported by any company, institution and/or government. The authors state 
sincere thanks to Department of Biotechnology, PRIST University, Thanjavur, Tamil Nadu, India, for providing lab and animal house facility. We express our gratitude to Prof. Dipankar Chatterji and Mr Sathish K, Molecular Biophysics Unit (MBU), Indian Institute of Science (IISc), Bangalore, Karnataka, India for providing MALDI-TOF-MS/MS facility as a paid service which helped the data analysis.

\section{REFERENCE}

Abel ED (2004) Glucose transport in the heart. Front Biosci 9: 201-215. Ahmed S, Reza MS, Jabbar A (1994) Antimicrobial activity of C. dactylon. Fitoterapia 65: 463-464.

Anderson L (2005) Candidate-based proteomics in the search for biomarkers of cardiovascular disease. J Physiol 563: 23-60.

Andreassen CS, Jakobsen J, Flyvbjerg A, Andersen H (2009) Expression of neurotrophic factors in diabetic muscle-relation to neuropathy and muscle strength. J Brain 132: 2724-2733

Ares-Carrasco S, Picatoste B, Camafeita E, Carrasco-Navarro S, Zubiri I, Ortiz A, Egido J, López JA, Tunon J, Lorenzo O (2012) Proteome changes in the myocardium of experimental chronic diabetes and hypertension; Role of PPAR $\alpha$ in the associated hypertrophy. I Proteomics 75: 1816-1829.

Atmani F, Sadki C, Aziz M, Mimouni M, Hacht B (2009) C. dactylon extract as a preventive and curative agent in experimentally induced nephrolithiasis. Urol Res 37: 75-82.

Auddy B, Ferreira M, Blasina F (2003) Screening of antioxidant activity of three Indian medicinal plants, traditionally used for the management of neurodegenerative diseases. J Ethnopharmacol 84: 131-138.

Barbacid M (1993) The Trk family of neurotrophin receptors: molecular characterization and oncogenic activation in human tumors, pp 123-136, Wiley-Liss, Inc., New York.

Bethel CM, Sciara EB, Estill JC, Bowers JE, Hanna W, Paterson AH (2006) A framework linkage map of bermudagrass (C. dactylon X transvaalensis) based on single-dose restriction fragments. Theor Appl Genet 112: 727-737.

Bradford MA (1976) Rapid and sensitive method for the quantitation of protein utilizing the principles of protein-dye binding. Anal Biochemistry 72: 248-254.

Cruz-Topete D, List EO, Okada S, Kelder B, Kopchick JJ (2011) Proteomic changes in the heart of diet-induced pre-diabetic mice. I Proteomics 74: 716-727.

Curcoy A, Olsen RKJ, Ribes A, Trenchs V, Vilaseca MA, Campistol J, Osorio JH, Andresen BS, Gregersen N (2003) Late-onset form of b-electron transfer flavoprotein deficiency. Mol Genet Metabol 78: 247-249

Donovan MJ, Lin MI, Wiegn P, Ringstedt T, Kraemer R, Hahn R, Wang S, Ibanez CF, Rafii S, Hempstead BL (2000) Brain derived neurotrophic factor is an endothelial cell survival factor required for intramyocardial vessel stabilization. Development 127: 4531-4540.

Garber DW, Neely JR (1983) Decreased myocardial function and myosin ATPase in hearts from diabetic rats. Am J Physiol 244: H586H591.

Hamblin M, Friedman DB, Hill S, Caprioli RM, Smith HM, Hill MF (2007) Alterations in the diabetic myocardial proteome coupled with increased myocardial oxidative stress underlies diabetic cardiomyopathy. J Mol Cell Card 42: 884-895.

Henriques BJ, Bross P, Gomes CM (2010) Mutational hotspots in electron transfer flavoprotein underlie defective folding and function in multiple acyl-CoA-dehydrogenase deficiency. Biochim Biophys Acta 1802: 1070-1077.

Herrick KR, Salazar D, Goodman SI, Finocchiaro G, Bedzyk LA Frerman FE (1994) Expression and characterization of human chimeric buman-Paracoccus denitrificans electron transfer flavoproteins. I Biol Chem 269: 32239-32245.

Hongfang L, Vasilij K, Emma MA, Armen VG, Michael B. Wheeler (2010) Molecular and metabolic evidence for mitochondrial defects associated with $\beta$-cell dysfunction in a mouse model of type 2 diabetes. J Diabetes 59: 448-459.

Ikeda Y, Keese SM, Tanaka K (1986) Biosynthesis of electron transfer flavoprotein in a cell-free system and in cultured human fibroblasts. Defect in the alpha subunit synthesis is a primary lesion in glutaric aciduria type II. J Clin Invest 78: 997-1002.

Kaisho Y, Yoshimura K, Nakahama K (1990) Cloning and expression of a cDNA encoding a novel human neurotrophic factor. FEBS Lett 266: 187-191.
Karthik D, Ravikumar S (2011a) A Study on the protective effect of Cynodon dactylon leaves extract in diabetic rats. Biomed Environ Sci 24: 190-199.

Karthik D, Ravikumar S (2011b) Proteome and phytochemical analysis of Cynodon dactylon leaves extract and its biological activity in diabetic rats. Biomed Prevent Nutri 1: 49-56.

Kim JA, Montagnani M, Koh KK, Quon MJ (2006) Reciprocal relationships between insulin resistance and endothelial dysfunction: molecular and pathophysiological mechanisms. Circulation 113: 18881904.

Kumar S, Tamura K, Nei M (2004) MEGA3: Integrated software for molecular evolutionary genetics analysis and sequence alignment. Brief Bioinform 5: 150-163.

Lam L, Lind J, Semsarian C (2006) Application of proteomics in cardiovascular medicine. Int J Cardiol 108: 12-19.

Langtry HD, Balfour JA, Glimepiride (1998) A review of its use in the management of type 2 diabetes mellitus. Drugs 55: 563-84.

Lien L, Joanne L, Christopher S (2006) Application of proteomics in cardiovascular medicine. Int J Cardiol 108: 12-19.

Lindvall O, Kokaia Z, Bengzon J, Elmer E, Kokaia M (1994) Neurotrophins and brain insults. Trends Neurosci 11: 490-496.

Liu Y, Liu W, Crooks K, Schmidt S, Allingham RR, Hauser MA (2010) No evidence of association of heterozygous NTF4 mutations in patients with primary open-angle glaucoma. Am J Hum Genet 86: 498-499.

Miraldi E, Ferri S, Mostaghimi V (2001) Botanical drugs and preparations in the traditional medicine of West Azerbaijan (Iran). J Ethnopbarmacol 75: 77-87.

Muthu C, M. Ayyanar N, Raja, Ignacimuthu S (2006) Medicinal plants used by traditional healers in Kancheepuram District of Tamil Nadu, India. J Ethanobio Ethnomed 2: 1-10

Nassenstein C, Braun A, Erpenbeck VJ, Lommatzsch M, Schmidt S, Krug N, Luttmann W, Renz H, Virchow JC (2003) The neurotrophins nerve growth factor, brain-derived neurotrophic factor, neurotrophin-3, and neurotrophin- 4 are survival and activation factors for eosinophils in patients with allergic bronchial asthma. J Exp Med 198: 455-467.

Noble D (2002) Modeling the heart-from genes to cells to the whole organ. Science 295: 1678-1682.

O'Farrell PH (1975) High resolution two-dimensional electrophoresis of proteins. J Biol Chem 250: 4007-4021.

Perkins DN, Pappin DJC, Creasy DM (1999) Probability-based protein identification by searching sequence databases using mass spectrometry data. Electrophoresis 20: 3551-3567.

Prince PS, Menon VP, Pari L (1998) Hypoglycemic activity of Syzigium cuminii seeds: effect on lipid peroxidation in alloxan diabetes rats. I Ethnopharmacol 61: 1-7.

Santosh KS, Prashant KR, Dolly J, Geeta W (2008) Evidence-based critical evaluation of glycemic potential of Cynodon dactylon. Evidencebased Complementary and Alternative Medicine 5: 415-4120.

Schott P, Jacobshagen C, Kohler J, Seidler T, Asif AR, Dihazi H, Hasenfuss G, Maier LS (2010) Proteome changes in CaMKII overexpressing cardiac myocytes. Cardiovascular Pathol 19: e241-e250.

Singh SK, Rai PK, Jaiswal D, Rai DK, Sharma B, Watal G (2008) Protective effect of Cynodon dactylon against STZ induced hepatic injury in rats. I Ecophysiol Occup Hlth 8: 195-199.

Tessarollo L (1998) Pleiotropic functions of neurotrophins in development. Cytokine Growth Factor Rev 9: 125-317.

Tuñón J, Martin-Ventura JL, Blanco-Colio LM, Lorenzo O, Antonio Lopez J, Egido J (2010) Proteomic strategies in the search of new biomarkers in atherothrombosis. I Am College of Cardiol 55; 20092016.

Uncini MRE, Tomei PE (1999) Ethnopharmacobotanical studies of the Tuscan Archipelago. J Ethnopharmacol 65: 181-202.

Wayne F, Patton (2002) Detection technologies in proteome analysis. J Chromatography B 771: 3-31

White MY, Cordwell SJ, McCarron HC, Prasan AM, Craft G, Hambly BD, Jeremy RW (2005). Proteomics of ischemia/reperfusion injury in rabbit myocardium reveals alterations to proteins of essential functional systems. Proteomics 5: 1395-1410.

White RA, Dowler LL, Angeloni SV, Koeller DM (1996) Assignment of Etfdh, Etfb, and Etfa to chromosomes 3, 7, and 13: the mouse homologs of genes responsible for glutaric acidemia type II in human. Genomics 33: 131-134.

Yan L, Ge H, Li H, Lieber SC, Natividad F, Resuello RR, Kim SJ, Akeju S, Sun A, Loo K, Peppas AP, Rossi F, Lewandowski ED, Thomas AP, Vatner SF, Vatner DE (2004) Gender-specific proteomic alterations in glycolytic and mitochondrial pathways in aging monkey hearts. J Mol Cell Cardiol 37: 921-929. 